\title{
Factors that influence the implementation of sustainable land management practices by rural households in Tigrai region, Ethiopia
}

\author{
Haftu Etsay ${ }^{*}$ (D), Teklay Negash and Metkel Aregay
}

\begin{abstract}
Background: Sustainable land management is considered as one of the useful approaches to combat the threat of various forms of land degradation in Ethiopia. Despite this, there is scant information regarding households' decision towards the implementation of sustainable land management practices. This paper, therefore, looks into the determinants for the continued use and choice of the sustainable land management practices by smallholder farmers and its productivity effect in three randomly chosen districts in Tigrai region, Ethiopia. The study uses data from household survey and key informant interviews. The paper employs a binary logit to analyze the determinants for the decision of continued use of sustainable land management practices, and a multivariate probit to analyze the simultaneous adoption decision of sustainable land management practices using cross sectional data collected from 230 randomly selected households. The impact of sustainable land management practices was also evaluated using propensity score matching.

Results: Farming techniques, wealth status, agro-ecological variations, and plot level characteristics were found to be associated with the implementation decision of sustainable land management practices by rural households. Besides, institutional supports and access to basic infrastructures influenced the overall continued use of sustainable land management practices and the preference of households toward these practices. The study also finds that the value of crop production of sustainable land management users was on average $77-100 \%$ higher than that of nonusers.

Conclusions: The results of the current study confirm that the implementation of various sustainable land management practices are influenced by farming technologies deployed by rural households, agro-ecological variations, plot characteristics, and institutional supports. The findings also affirm that most of the sustainable land management practices are complementary to one another, and implementing two or more sustainable land management practices on a given plot is highly associated with higher value of crop production. Such complementarity highlights that the productivity effect of a given sustainable land management practice is enhanced by the use of the other ones.
\end{abstract}

Keywords: Continued use, Determinants, Plot level, Productivity effect, Sustainable land management practice, Tigrai

\footnotetext{
* Correspondence: haftu04@gmail.com

Department of Agricultural and Resource Economics, College of Drylands

Agriculture and Natural Resources, Mekelle University, Mekelle, Ethiopia
} 


\section{Introduction}

Land degradation has been the critical challenge for Sub-Saharan African (SSA) countries. The causes of land degradation are complex and vary from place to place. The major drivers of land degradation are generally grouped into two: proximate and underlying causes (Belay et al. 2015; Pingali et al. 2014). The proximate causes are more or less natural factors such as biophysical conditions, topographic and climatic conditions, and inappropriate land management practices, whereas the underlying factors are mostly anthropogenic, which include population growth, land tenure, and other socioeconomic and policy related factors (Belay et al. 2015; Pingali et al. 2014).

FAO (2011) report shows that Africa loses over 50 tons of soil per hectare and nearly 4 million hectares of forest land annually, largely in humid and sub-humid West Africa. These evidences indicate that the natural resources in the continent have been excessively utilized and this resulted in land degradation which in turn affects the livelihood of African farmers as the majority of them rely on the direct use of natural resources for their very survival. The key drivers of land degradation in Africa in general and in sub-Saharan Africa in particular are similar to that of at global scale which include high demographic growth, weak incentive policy, poor legal and institutional frameworks, limited availability of grazing land, and poor knowledge regarding the environment (Diagana 2003; Hurni et al. 2010). Especially in countries with limited cultivable land and high population growth rates, fallow periods are no longer sufficient to allow soil fertility to be restored. Kenya, Ethiopia, Malawi, Burundi, and Rwanda are examples of this where crop yields have fallen consequently. In a response, farmers have been forced either to bring increasingly marginal lands into cultivation, or to migrate into tropical forest areas, exacerbating problems of land degradation and deforestation (FAO, 2011). The economic consequences of land degradation are also severe in Eastern Africa since nearly $65 \%$ of the population is rural and the main livelihood of about $90 \%$ of these rural populations relies on subsistence based agriculture (Kirui and Mirzabaev 2015).

The level of degradation in many SSA, including Ethiopia, is even more severe. Besides, addressing the proximate and underlying causes of the prevailing land degradation problems remains a critical policy challenge for Ethiopia since its economy enormously relies on subsistence agriculture. The major drivers of land degradation in Ethiopia include land shortage and lack of alternative livelihoods (induced by high population growth), forest clearance and high removal of vegetation cover, unsustainable cultivation practices, and overgrazing (FAO, 2011). Soil erosion and deforestation are the two more severe forms of land degradation that contribute to the poor performance of subsistence agriculture sector in Ethiopia (Bekele and Drake 2003; Bewket 2003). These land degradation problems have also far-reaching economic, social, and environmental influences (Pender and Gebremedhin 2007). With regard to cost of land degradation, various estimates show that it costs a considerable proportion of a country's national income. In Ethiopia, for instance, the cost of land degradation was about 3\% of the total agricultural GDP in 1994 (Bojo and Cossells 1995). Sustainable land management, has, therefore, utmost importance to Ethiopia in which about $80 \%$ of its population is directly supported by the agriculture sector. It addresses land degradations and enhances the productive capacity of the natural resources base. In addition, in the absence of effective sustainable land management (SLM) practice, it is less likely to eradicate poverty (von Braun et al. 2014).

A number of studies have addressed important influencing factors that explain the adoption decision behavior of smallholder farm households toward various land conservation measures. For instance, a study conducted in north western part of Ethiopia by Adugna and Bekele (2007) revealed that economic variables such as plot ownership, livestock holding, family size, and land-to-labor ratio have an influence on adoption of land conservation practices. Furthermore, the major socioeconomic factors that influence households decision to adopt soil and water conservation measures in Ethiopian highlands include sex and education level of household head, availability of labor force, cattle holding, and off/ non-farm income (Adimassu and Kessler 2012; Amsalu and de Graaff 2007; Bekele and Drake 2003). On the other hand, biophysical characteristics of plots, topography, and agro-ecological variations also influence the adoption decision of soil and water conservation and other sustainable land management practices (de Graaff et al. 2008; Miheretu and Yimer 2017). World Bank (2007) and Yirga (2007) also reported that institutional factors such as land insecurity, access to credit, proximity to all weather road, and market access were likely to influence the adoption of and investments on sustainable land management practices in Ethiopia. The adoption of SLM practices by farm households has also been hurdled by wealth-related factors (von-Braun et al. 2013; Bewket 2007; Genanew and Alemu 2012; Shiferaw and Holden 1998). Furthermore, Amsalu and de Graaff (2007) revealed that the adoption level of SLM practices by self-motivated farmers remains very low and yet to bring the intended results in terms of improving the livelihoods of rural households.

With regard to the effectiveness of sustainable land management practice, mixed results have been reported particularly related to its impact on crop yield of farm 
plots. A study by Pender and Gebremdhin (2006), for instance, reported that farm plots that are treated with stone terraces experience a significant yield increment. Besides, an impact evaluation study conducted in Northern Ethiopia at household level revealed that those who introduced stone bund on their private plots experienced higher value of crop production as compared to those who did not (Kassie et al. 2008). Nevertheless, other studies revealed that the outcome of series of conservation measures introduced in Ethiopia, usually involving physical and biological structures such as terraces, bunds, and tree planting, among others, is less than desired (Berry 2003; Eyasu 2003). Besides, an inverse relationship between adoption of SLM practices and crop yield was found in areas characterized by high rainfall in western part of Amhara regional state of Ethiopia (Kassie et al. 2008).

There is also destruction of soil and water conservation structures in many parts of Ethiopia (Kassie 2009; Tadesse and Belay 2004) which pose a critical challenge on the sustainability of the already introduced land conservation measures. Such discrepancy of findings shows that the impact of SLM practice on the productivity of farm plots and level of acceptance varies across different landscapes and agro-ecological zones. The effectiveness of the introduced SLM practices on farmlands has been challenged by many factors such as inappropriate implementation approaches, too much focus on technical solutions, too little focus on addressing the proximate and undelaying causes of land degradations, and poor extension systems (Adimassu et al. 2016; Adimassu and Kessler 2012; Kassie 2009; Bewket 2007; Bekele 2003). Additional contributors to the ineffectiveness in terms of attaining the required results include top-down planning methodology, lack of community input, and low implementation capacity at local levels (Tongul and Hobson 2013). There are also evidences that policy-related challenges have contributed to the failure of land conservation efforts in terms of achieving the intended objectives in different parts of the country. For example, the findings of Nkonya et al. (2013) and von Braun et al. (2013) indicate that lack of strong policy action and low level of evidence-based policy framework are considered to be the critical challenges for the effectiveness of SLM practices.

As reviewed earlier, despite the abundance of research works in SLM and its crop productivity effect, the studies are extensively oriented towards the initial adoption but with no consideration to the continued use and multiple adoption decision of SLM practices. Most of the previous studies modeled the adoption of SLM practice as a binary: adopters and non-adopters. Such modeling would make it difficult to analyze the preference of households towards various SLM practices and simultaneous adoption decisions. Therefore, studying the simultaneous adoption behavior of farmers and the intensity of the use of SLM practices would be helpful to the existing body of knowledge. This is true since farmers are more likely to use a combination of SLM practices to deal with the land degradation problems faced instead of adopting just only a single conservation practice. The adoption decision is, therefore, explained in the form of preferences from a set of land conservation options. To this effect, a multivariate instead of bivariate approach, which excludes useful information contained in the interdependent and simultaneous adoption decisions, is employed to model the adoption decision. This paper, therefore, intends to examine the factors affecting households' decision to the implementation of multiple SLM practices and the productivity effect on farmlands as it would help to better understand the households' decision behavior towards land management practices on farm plots as well as institutional and biophysical factors that affect such decisions.

\section{Methods \\ Study sites}

The current study was conducted in three randomly selected districts ${ }^{1}$ of Tigrai region, namely Atsibi-wenberta, Hintalo-wajerat, and Kola-tembien representing highland, midland, and lowland agro-ecological zones respectively as shown in Fig. 1. The first step in the random sampling procedure of the districts was obtaining the list of districts in the region based on their agro-ecological classification. Then after, one district from each ago-ecological zone, which makes up a total of three districts, was randomly selected using a lottery system. The study communities including the catchment areas within each selected district were purposively chosen using predefined criteria stated below. Lastly, the respondents from the selected catchments, both from treated and untreated, were randomly drawn using a lottery system. The total rural districts in the region are 34 in which sustainable land management practices have been implemented since the past few decades. This study selects three districts randomly (a lottery system) in which an attempt was made to represent the three agro-ecological zones (highland, midland, and lowland).

The study sites are spatially distributed across three districts of the region to capture heterogeneous data on both socioeconomic and plot level biophysical attributes. The study sites are also characterized by various climatic and topographic domains ranging from altitude differences to temperature and rainfall variations as well as cropping patterns.

Kola-tembien is topographically located with a range of 1501 to $2500 \mathrm{~m}$ above sea level. The estimated annual rainfall ranges from 500 to $800 \mathrm{~mm}$, while mean annual 


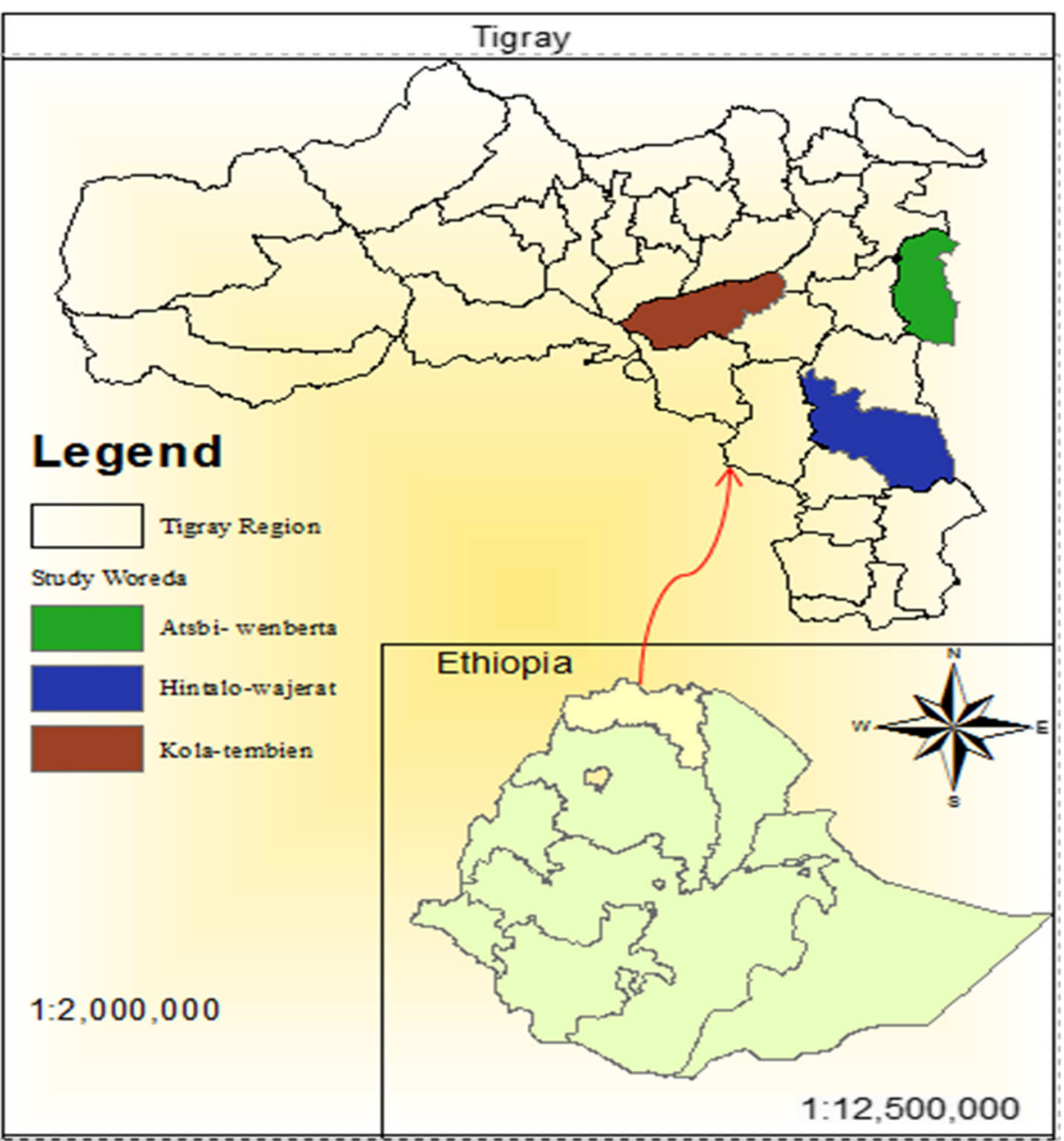

Fig. 1 Location of study sites

temperature varies between 25 and $30{ }^{\circ} \mathrm{C}$. The wereda is administratively divided into 27 tabias. The total population of the wereda is 148,282 and the total area is estimated at 147,427 ha. On the other hand, Atsibi-wenberta is subdivided into 16 administrative tabias with a total population of 112,341. The elevation of Atsibi-wenberta wereda varies significantly which ranges from 918 to $3069 \mathrm{~m}$ above sea level. The third study site (Hintalo-wajerat wereda) has a total population of 153,505 with 34,360 households and an area of $2864.79 \mathrm{~km}^{2}$. This wereda is situated at an altitude range of 1500 to $2540 \mathrm{~m}$ above sea level. In addition, the wereda is divided into 20 administrative tabias.

The farming system was observed to be a mix of livestock and crop production which is fairly similar in the three study sites. The dominant crops grown by smallholder farmers in Kola-tembien district, for instance, are teff, sorghum, maize, and finger-millet. In Hintalo-wajert district, the staple crops grown are wheat, barley, and teff. Similarly, the dominant crops grown in
Atsibi-wenberta district are wheat, barley, and pulses. The livestock production system is also fairly similar across the three study weredas. It is mainly characterized by traditional husbandry system with small per capita cattle holding, sheep, and goat and to some extent poultry production. The production system of both crop and livestock is characterized by low input and low output which indicates the farming system has remained very traditional and subsistence.

\section{Data and sampling procedures}

The current study selected three catchment areas as treated observations and another three catchment areas as control observations using multi stage sampling techniques. In the first stage of the sampling procedure, the three districts were randomly selected using a lottery system from a list of all districts found in the region. Then after, using predefined criteria, ${ }^{2}$ a total of three tabias $^{3}$, which includes one tabia from each selected district that best fits the criteria, were purposively 
chosen with the support of experts from the office of natural resource management of the study districts. Lastly, a model catchment area from each selected tabia was purposively selected based on the stated criteria. The list of selected tabias and catchment areas are presented in Table 1. For comparison purpose, one catchment area, ${ }^{4}$ which is considered to be poorly conserved by SLM practices, from each tabia was also selected. The target population for this study was households who introduce SLM practice on their plots in the absence of any external incentive and also continues to maintain the conservation measures. Representative sample size was finally determined using Eq. 1, and respondents were selected through a lottery system of simple random sampling. The lottery system was done through the help of Microsoft Excel which enables to generate a random number from the data set of the sampling frame. The distribution of the sample size across the study sites was proportionate to their relative share of the total sampling frame (target population) as shown in Table 1.

This paper is based on a survey of 230 randomly drawn households from a set of list of household heads of three tabias and six catchments. The required data were collected using structured questionnaire from the selected heads of households. The study prepared two separate set of questions for the household survey (structured questionnaire) and for the key informant interviewees (checklist and few unstructured open ended questions). A structured questionnaire was designed to elicit information on demographic, socioeconomic, infrastructure, and plot level information from the households, whereas the key informant interview (KII) was designed to gather qualitative data on the challenges of maintaining conservation structures, benefits of sustainable land management practices, and institutional supports to promote SLM.

A check list was used to gather data from the key informants that include natural resource management experts, development agents, and tabia leaders of the study sites. The participants of the KII were development agents and community leaders from the three tabias included in this study who are better informed and can better describe about the sustainable land management practices in their localities. A pre-test survey was conducted prior to the actual survey in each study site to incorporate unforeseen variables and also for acclimatization purpose. Following this, training on the questionnaire and over all data collection was provided to the enumerators. The secondary data were obtained particularly from unpublished reports of the office of the natural resources management of the study sites.

$$
n=\frac{p(1-p)}{\frac{e^{2}}{Z^{2}}+\frac{p(1-p)}{N}}
$$

Where $n$ is the sample size, $N$ is the population size (171), $Z$ is the confidence level at $95 \%, Z=1.96$, and $P$ is the estimated population proportion (50\%), precision level $(e)=0.06$. The total representative sample size was found to be approximately 115 households and a reasonable sample size was taken from each catchment in proportion to their representation to the total target population (Table 1). In addition, 115 households who do not introduce SLM measures on their plots were randomly selected as control observations. The selected comparison catchment areas for controlling purpose (where the control observations were selected) are spatially located adjacent to the catchment areas where continued users of SLM practices reside. An attempt was also made to include catchments (for the treated observations) that had been treated at least 2 years prior to the survey with an intention that this time lag provides adequate time for households to develop the experience needed to operate and manage SLM practices and at the same time experience the benefits of the continued use of SLM practices on farmlands.

\section{Data analysis}

Both descriptive and inferential statistics method of data analysis were employed. Particularly, mean, standard deviation, $t$ tests, and chi square tests were used to analyze data collected from the sample households. Binary logit and multivariate probit were deployed to analyze the drivers to the households' decision toward the continued use and choices of SLM practice by farm households respectively. Propensity score matching was also deployed to evaluate the impact of introduced SLM practices on the value of crop production. The data collected from the key informants was qualitatively analyzed using content analysis and the results are integrated with the

Table 1 Distribution of respondents by study tabia and catchment (districts in parentheses)

\begin{tabular}{|c|c|c|c|c|c|c|}
\hline Agro-ecological zone & Selected tabia & Selected catchment & Total SLM users & Treated observation & Control observation & Total sample \\
\hline Highland & Kaal-amin (Atsibi-wonberta) & Ambelten & 55 & 37 & 37 & 74 \\
\hline Midland & Hintalo (Hintalo-wajerat) & May-derhu & 64 & 43 & 43 & 86 \\
\hline Lowland & Begashka (Kola-tembien) & Shimderena & 52 & 35 & 35 & 71 \\
\hline Total & & & 171 & 115 & 115 & 230 \\
\hline
\end{tabular}


empirical (quantitative approach) results as the main objective of its inclusion is to support the empirical findings using a qualitative approach.

\section{Binary logit model}

The determinant factors for the continued use of SLM practices were estimated using a binary logit regression. Following Garson (2008), which applies maximum likelihood estimation after transforming the dependent into a logit variable, the classification of households into a binary model, continued user and non-user, was done based on households' past experiences in SLM practices (Table 2). The dependent variable, which is the natural $\log$ of the odds (logit), is binary as shown in Eq. 2 . Households whose farm plot/s is/are well conserved and regularly maintained with the introduced terraces and other modern conservation measures were considered as continued users in this analysis. On the other side, households who are reluctant to maintain the introduced conservation structure (previously introduced by a project assistant or mass mobilization) were labeled as non-continued users. The binary choices in this case are households that adopted and are also continuously maintaining the introduced terraces $(Y=1)$ and households that had removed/or reluctant to maintain conservation measures built in the past $(Y=0)$.

$$
\begin{aligned}
\ln \left(\frac{\mathrm{p}}{1-\mathrm{p}}\right) & =a+b x \\
p & =\frac{e^{a+b x}}{1+e^{a+b x}}
\end{aligned}
$$

Where $P$ denotes the probability of the event occurring, $X_{i}$ denotes the independent variables, $e$ is the base of the natural logarithm, and $a$ and $b$ are the parameters of the model.

A dummy variable $Y$ was used to identify whether each sampled household is a continued user of SLM practice or not.
$Y=1$ for the continued user and $Y=0$ otherwise

$X_{i}$ denotes for independent variables (explanatory variables that might affect the households' decision to continually use SLM techniques).

The reduced formal used in this logistic regression model is shown in Eq. 3.

$$
\begin{aligned}
Y= & \ln (\text { odds }(\text { event })) \\
= & \ln (\operatorname{prob}(\text { event } / \operatorname{prob}(\text { nonevent })) \\
= & \ln (\operatorname{prob}(\text { event } /[1 \text {-prob }(\text { event })] \\
= & b_{0}+b_{1} X_{1}+b_{2} X_{2}+b_{3} X_{3} \\
& +\ldots+b_{n} X_{n}+\varepsilon_{i}
\end{aligned}
$$

Where $b_{0}$ is the constant and $Y$ is continued use of SLM technologies $=\operatorname{Pr} Y(1=$ a household chooses to continually practice SLM technologies, $0=$ otherwise).

$b_{1} \ldots b_{n}$ is the estimated coefficients, and $\varepsilon_{i}$ is an error term

$X_{1 . .} X_{n}=$ vectors of explanatory variables included in the model

The full list of explanatory variables included $\left(X_{1 . . .} X_{n}\right)$ in the binary logit and multivariate probit models along with their descriptions are presented in Table 3. It is important to note that some of the classifications regarding the households' perception towards plot level attributes could be relatively weak due to subjectivity of respondents, such as categorization of soil fertility into good, medium, and poor as well as slope (steep, medium and gentle). We suspect it can have some influence on the precision level of the results.

\section{Multivariate probit}

Following Cappellari and Jenkins (2003), the current study used a multivariate probit model to analyze the determinant factors for the choice of SLM practices using Eq. 4. The reason behind the use of multivariate probit (MVP) ${ }^{5}$ is due to the premises that farmers use a

\begin{tabular}{|c|c|c|}
\hline Type of SLM measures ${ }^{a}$ & Description & Source \\
\hline $\begin{array}{l}\text { Physical soil and } \\
\text { water conservation }\end{array}$ & Structures that are implemented on farm plots such as soil and stone bund, terraces and trenches & WOCAT 2005; GIZ 2014 \\
\hline Agroforestry practice & Growing multi-purpose trees on farm plots such as fruit trees, animal fodder, and the like & $\begin{array}{l}\text { WOCAT 2005; GIZ 2014; } \\
\text { Kirui and Mirzabaev } 2015\end{array}$ \\
\hline Agronomic practice & $\begin{array}{l}\text { Include activities that aim at production and conservation at a time. It includes compost } \\
\text { and manure application and other soil fertility management practices }\end{array}$ & GIZ 2014; WOCAT 2005 \\
\hline $\begin{array}{l}\text { Indigenous } \\
\text { conservation }\end{array}$ & $\begin{array}{l}\text { Conservation measures that are originated from the local people and that have been } \\
\text { practiced for a long time. It includes contour plowing, crop rotation, and fallowing }\end{array}$ & WOCAT 2005; FAO 2011 \\
\hline
\end{tabular}
combination of any of the SLM practices instead of relying on a single conservation practice to reduce their land degradation problems in which the SLM options can be a complement or a substitute to one another (Kassie et al. 2013; Teklewold et al. 2013).

Table 2 Classification of SLM practices implemented on farmlands

${ }^{a}$ Physical soil and water conservation, agro-forestry, and agronomic practice are relatively standardized conservation measures that are promoted by the agricultural and natural resources management extension systems, while the indigenous conservation measures are not standardized and rely on local knowledge. This classification focuses on SLM measures that are dominantly practiced on farm plots by individual households in the study sites. 
Table 3 Description of explanatory variables included in the binary logit and MVP models

\begin{tabular}{|c|c|c|c|}
\hline $\begin{array}{l}\text { Explanatory } \\
\text { variables }\end{array}$ & $\begin{array}{l}\text { Type of the } \\
\text { variable }\end{array}$ & $\begin{array}{l}\text { Expected relationship (for binary } \\
\text { logit) }\end{array}$ & Description of the variable \\
\hline Yearsh & Continuous & + & Years of schooling of the household head \\
\hline Aghhd & Continuous & $+/-$ & Age of the household head in years \\
\hline Family size & Continuous & $+/-$ & Family size of the household \\
\hline HhdlF & Continuous & + & Size of labor force in the household \\
\hline Sex & Binary & $+/-$ & Sex of the household head ( $1=$ male, $0=$ female) \\
\hline Plot size & Continuous & $+/-$ & Total size of plots owned by the household in tsimad ${ }^{a}$ \\
\hline Off farm & Continuous & - & $\begin{array}{l}\text { Total off and non-farm incomes of the household (ETB/year), ETB is cur- } \\
\text { rency of Ethiopia }\end{array}$ \\
\hline TotVAST & Continuous & + & Total value of assets owned by the household in ETB \\
\hline Cattlholding & Continuous & - & Number of heads of cattle owned in TLU \\
\hline Crop yield & Continuous & + & Total crop produce in 2016/17 production year in quintal \\
\hline Farm input & Continuous & + & $\begin{array}{l}\text { The value of farm inputs employed by the household in 2016/17 } \\
\text { production year in ETB }\end{array}$ \\
\hline Slope & Categorical & $+/-$ & Slope of the plot ( 1 = gentle, 2 = medium, $3=$ steep $)$ \\
\hline Soil fertility & Categorical & + & Fertility status of the soil $(1=$ good, $2=$ medium, $3=$ poor $)$ \\
\hline Soil type & Categorical & $+/-$ & Type of soil ( 1 = clay, 2 = silt, 3 = sandy $)$ \\
\hline Plot location & Continuous & - & The distance between the house and the plot of a household in $\mathrm{Km}$ \\
\hline Agro-ecology & Categorical & $+/-$ & $\begin{array}{l}\text { Agro-ecological zone }(1=\text { Kaal-amin (highland), } 2=\text { Hintalo(midland), } \\
3=\text { Begashka (lowland) })\end{array}$ \\
\hline Position & Binary & $+/-$ & Participation in the community administration organs $(1=$ yes, $0=$ no $)$ \\
\hline Extension service & Continuous & - & Distance between residency and farmers training center in $\mathrm{km}$ \\
\hline Tenure security & Binary & + & Land certification ( $1=$ yes, $0=$ no) \\
\hline Credit access & Binary & + & Access to credit services $(1=$ yes, $0=$ no $)$ \\
\hline Infonaccess & Binary & + & Access to mass media ( $1=$ yes, $0=$ no $)$ \\
\hline Irrnaccess & Binary & + & Access to irrigation facility $(1=$ yes, $0=$ no $)$ \\
\hline Zero grazing & Binary & + & Practicing zero grazing ( $1=$ yes, $0=$ no $)$ \\
\hline Market access & Continuous & - & Distance to nearest market in $\mathrm{km}$ \\
\hline $\begin{array}{l}\text { Dependent variable } \\
\text { in logit model }\end{array}$ & $\begin{array}{l}\text { Continued use of } \\
\text { SLM practices }\end{array}$ & & $1=$ continued user, 0 otherwise \\
\hline $\begin{array}{l}\text { Dependent variable } \\
\text { in MVP }\end{array}$ & $\begin{array}{l}\text { Choice of SLM } \\
\text { practices }\end{array}$ & & $\begin{array}{l}\text { Indigenous }(1=\text { yes, } 0=\text { no }) \text {, physical }(1=\text { yes, } 0=\text { no }) \text {, agro-forestry } \\
(1=\text { yes, } 0=\text { no), agronomic conservation }(1=\text { yes, } 0=\text { no })\end{array}$ \\
\hline
\end{tabular}

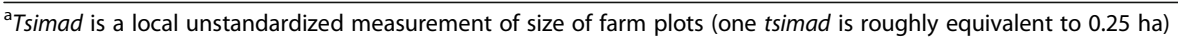

The current study grouped the various sustainable land management options implemented on farm plots into four major classifications. There are a number of SLM practices which make it very difficult to separately analyze the choice of farmers towards these options at a time. The details on the grouping along with their descriptions are presented in Table 2.

$$
\begin{aligned}
y_{i m}^{*} & =\beta_{m} x_{i m}+\varepsilon_{i m}, \quad y_{i m}=1 \text { if } y_{i m}^{*} \\
& >0 \text { and } 0 \text { otherwise }
\end{aligned}
$$

Equation 4 is based on the assumption that a rational $i$ th farmer has a latent variable $y_{i m}^{*}$ which captures unobserved preferences associated with the $m$ th choice of SLM measures $(m=$ the four available SLM practices used in this study); $\beta_{m}$ is the set of parameters that reflect the impact of changes in the vector of explanatory variables $x_{\mathrm{i}}$ on the farmer's preference toward the $m$ th SLM practices; $x_{\mathrm{im}}$ represents the vector of observed variables that are expected to explain each type of SLM practice; and $\varepsilon_{\mathrm{im}}$ represents error terms following a multivariate normal distribution, each with a mean of zero and a variance covariance matrix with values of 1 on the leading diagonal and non-zero correlations as off-diagonal elements.

\section{Propensity score matching}

The present study took a closer look at the impact of the introduced conservation practices on the value of crop production at household level since the ultimate 
objective of the conservation of private farm plots is to enhance its productivity. To this end, propensity score matching was used to compute the impact that the SLM measures have brought on the value of production for users compared to non-users. The study employed four matching algorisms, namely nearest neighbor, radius, kernel, and stratification to evaluate household and plot level impacts of introduced SLM practices on the value of crop production. Monetary value was used as a standard unit to measure the impact on crop yield as households cultivate more than one crop which makes it difficult to see the effect on the aggregate physical quantity of crop yield. We denote continued users of SLM practices as $Y_{1}$ and non-continued users as $Y_{0}$, whereby the impact of SLM practices is the difference in value of crop production between continued and non-continued users $\left(\Delta=Y_{1}-Y_{0}\right)$. And treatment $D$ is a binary variable that determines if a household is a continued SLM user or not, $D=1$ for the SLM continued user households and $D=0$ otherwise. Then we find the average impact of the SLM practice on the value of crop production, in the jargon of propensity score matching (PSM) called average treatment effect on the treated observations.

(ATT) using Eq. 5.

$$
\begin{aligned}
\mathrm{ATT} & =(E(\Delta) \mid p(x), D=1) \\
& =E\left(y_{1} \mid p(x), D=1\right)-E\left(y_{0} \mid p(x), D=0\right)
\end{aligned}
$$

\section{Results}

\section{Description of the respondents}

The mean and percentage values of the socioeconomic and demographic characteristics of the surveyed households are presented in Table 4. The two sample $t$ tests confirmed that a significant difference was observed in asset holding and livestock ownership measured in terms of tropical livestock unit (TLU) between continued users and non-users of SLM practices. This indicates that farmers with relatively higher ownership of asset and livestock holding tend more to adopt SLM practices than those whose ownership is relatively smaller. On the other side, the majority of sociodemographic attributes of the two groups, such as age, sex composition, level of educational attainment, family size, and land holding, show no statistically significant differences. Male-headed households accounted for about $78.3 \%$ of the total respondents, while female-headed households accounted for about $21.7 \%$ with no significant difference between SLM users and non-users $(p=0.7)$. The average family size of the surveyed households was six with no significant difference between users and non-users.

The average ages of continued user and non-user respondents were 45.5 and 44.5 years respectively while it was 45 years for the total respondents. The average total value of asset of respondents was 67,135.5 ETB with a statistically significant difference $(p<0.010)$ between the continued users and non-users of SLM practices (Table 4). About $80.1 \%$ of the total respondents were married and the remaining $19.9 \%$ were divorced, widowed, and single in aggregate. The average year of schooling was 3 years with no significant difference between the two groups. On average, the household heads of the surveyed respondents attended 3 years of schooling which indicates that majority of them can, at least, read and write. Table 4 also shows that there was a statistically significant difference $(p<0.05)$ on cattle holding between the continued users and non-users of SLM practices which is 4.7 and 3.4 in TLU respectively, while the average for the total sample was 4 . This implies that households with large number of livestock holding are more willing to continually use SLM practices than those with relatively smaller cattle holdings. This might be due to the fact that some of the conservation

\begin{tabular}{|c|c|c|c|c|}
\hline Variables & $\begin{array}{l}\text { SLM users }(n=115) \\
\text { Frequency }(\%)\end{array}$ & $\begin{array}{l}\text { Non-SLM users }(n=115) \\
\text { Frequency }(\%)\end{array}$ & $\begin{array}{l}\text { Total }(n=230) \\
\text { Frequency }(\%)\end{array}$ & $t$ value/ $p$ value \\
\hline \multicolumn{5}{|l|}{ Sex of the household head } \\
\hline Male headed & $91(79.1)$ & $90(77.6)$ & $181(78.35)$ & -10.7 \\
\hline Female headed & $24(20.87)$ & $26(22.4)$ & $50(21.65)$ & -10.7 \\
\hline \multicolumn{5}{|l|}{ Continues variable } \\
\hline Age (average in years) & 45.5 & 44.5 & 45 & $0.4 / 0.34$ \\
\hline Average family size of households & 6 & 6 & 6 & $0.05 / 0.47$ \\
\hline Education (average years of schooling) & 3 & 3 & 3 & $0.05 / 0.47$ \\
\hline Average value of asset of households (ETB) ${ }^{a}$ & $78,483.6$ & $55,885.2$ & $67,135.5$ & $1.97 / 0.02$ \\
\hline Average land holding size in Tsimad & 3 & 3 & 3 & $0.01 / 0.49$ \\
\hline Average cattle holding in TLU & 4.7 & 3.4 & 4 & $3.6 / 0.000$ \\
\hline
\end{tabular}

Table 4 Description on the profile of surveyed households

${ }^{a}$ Ethiopian birr, currency of Ethiopia (US\$1 = 23.4 ETB as at August 2017 exchange rate) 
practices introduced on farmlands such as grasses and forage trees can be a source of feed for the livestock. The socioeconomic description has also shown that the average land holding of households is roughly about three tsimad with no significant difference between the two groups. This also further indicates that land size has nothing to do with the decision of a household to continually use SLM practices in the study area.

\section{SLM practices implemented on farmlands}

Table 5 presents the level of participation of the respondents towards the sustainable land management practices across the study sites. In Atsibi-wenberta wereda, for instance, the majority of the respondents $(80 \%) \mathrm{im}$ plemented physical soil and water conservation such as stone bund and terraces with small trenches, while $43 \%$ of the surveyed households use agronomic measures mainly manure application. As also evidenced in the same table, $25.5 \%$ of the respondents implemented more than one SLM practice on the same plot. However, in this wereda, only small proportion (2.5\%) of the respondents implemented agroforestry on their farmlands. Similarly, in Hintalo-wajerat wereda households who introduced physical structures, agroforestry, and agronomic measures accounts for $20.2,2$, and $40.5 \%$ of the total respondents, respectively. In this wereda, households tend to use more than one SLM practices as compared to the other two weredas, i.e., $35.7 \%$ of the surveyed households implemented two or more conservation practices (Table 5). The households in Kola-tembien have showed much interest to implement agronomic practices such as application of manure (67\% of the respondents).

The above depicted figures can give very useful insights regarding the types of SLM practices implemented in different ago-ecological zones. For instance, households in the highlands tend to practice stronger conservation measures mainly physical soil and water conservation as compared to those in the lowlands. This might be because the topography of the highlands is full of rugged terrains where acute soil erosion is evident as a result of excessive runoff. In the lowlands where the land is dominantly flat, on the other hand, agronomic conservation is the prioritized conservation approach. The result also shows that a significant proportion of the total respondents implement at least two conservation practices on a given plot, which of course is very important for augmenting farmland productivity since one conservation practice complements the other. Nonetheless, the use of agroforestry practice on farm lands by the respondents of all study sites seems to remain very low as depicted in Table 5.

\section{Factors affecting the continued use of SLM practices}

The binary logistic regression of the present study confirms that the model is fit and highly significant $\left(\right.$ Prob $>\mathrm{chi}^{2}=$ 0.001). Furthermore, the Hosmer-Lemeshow test of goodness of fit also fails to reject the null hypothesis which signals that the model is fit to the data (Table 6). The results of the binary logit regression show that 10 out of the 22 variables included in the model significantly affected the continued use of SLM practices by rural households. Households' resource endowments mainly availability of labor force, land holding, crop production, and farm input utilization were found to have an influence on the continued use of SLM practices. Besides, plot level characteristics such as soil fertility status, slope of plots, and location of the plot influence the continued use of SLM practices. Particularly, the study shows that the uptake of farm inputs, plot location, and distance to agricultural extension services are the most important predictors for the continued use of SLM practices in the study sites, and their odds ratios are interpreted in the subsequent paragraphs.

The availability of labor force was found to have a significant positive influence on farmers' decision to continuously use conservation measures on private farm plots. Table 6 shows that as labor force increases by one person (adult equivalent), the odds ratio of the probability of a household to continually conserve its plots also increases by a factor of $1.2(p<0.02)$.

The effect of the size of farm plots owned by a household on the decision to conserve of plots was statistically significant $(p<0.1)$. An increase in the size of a farm plot by one tsimad results in a decrease in the likelihood

Table 5 SLM practices implemented by households on farmlands

\begin{tabular}{|c|c|c|c|}
\hline \multirow{2}{*}{$\begin{array}{l}\text { Type of SLM practice implemented } \\
\text { by farm households }\end{array}$} & \multicolumn{3}{|c|}{ Study weredas/districts } \\
\hline & $\begin{array}{l}\text { Atsibi-wenberta } \\
\text { (\% of respondents) }\end{array}$ & $\begin{array}{l}\text { Hintalo-wajerat } \\
\text { (\% of respondents) }\end{array}$ & $\begin{array}{l}\text { Kola-tembien } \\
\text { (\% of respondents) }\end{array}$ \\
\hline $\begin{array}{l}\text { Physical soil and water conservation structures } \\
\text { (stone bund and other terraces) }\end{array}$ & 80 & 20.2 & 58 \\
\hline $\begin{array}{l}\text { Agroforestry (growing of fruit trees or other } \\
\text { multi-purpose trees) }\end{array}$ & 2.5 & 2 & 3 \\
\hline Agronomic measures (manure application) & 43 & 40.5 & 67 \\
\hline $\begin{array}{l}\text { Combination of any of two or more of the } \\
\text { above SLM practices }\end{array}$ & 25.5 & 35.7 & 33 \\
\hline
\end{tabular}


Table 6 Binary logit results on determinants for the continued use of SLM practices

\begin{tabular}{llll}
\hline Explanatory variables & \multicolumn{2}{l}{ Dependent variable (continued use of SLM practices) } & $p$ value \\
\cline { 2 - 4 } & Odds ratio ${ }^{\text {a }}$ & Standard error & 0.02 \\
\hline Availability of labor force & 1.2 & 0.09 & 0.08 \\
Plot size & 0.77 & 0.11 & 0.005 \\
Crop yield & 1.1 & 0.038 & 0.002 \\
Uptake of farm inputs & 1 & 0.000 & 0.024 \\
Good soil fertility status (poor as a reference) & 3.204 & 1.6 & 0.035 \\
Medium soil fertility status (poor as a reference) & 2.371 & 0.972 & 0.000 \\
Plot location & 0.976 & 0.006 & 0.027 \\
Hintalo (Begashka as a reference) & 4.5 & 3.08 & 0.033 \\
Kaal-amin (Begashka as a reference) & 3.689 & 2.257 & 0.01 \\
Distance to agricultural extension office & 0.979 & 0.008 & 0.84 \\
Constant & 1.408 & 2.397 & Prob > chi ${ }^{2}=0.000$ \\
Model summary & Log likelihood = - 117.62 & Hosmer-Lemeshow test $=0.18$ \\
\hline
\end{tabular}

${ }^{a}$ Odds ratio $<1$ represent negative relationship, whereas $\geq 1$ represent positive relationship

of a household to continuously conserve his/her plots by a factor of 0.77 (Table 6).

The amount of modern farm input utilization, particularly fertilizers, was also positively associated with the continued use of SLM practices by self-motivated farm households. As the expenditure on farm input increases by one Ethiopian Birr (currency of Ethiopia), the odds ratio of the likelihood of farm plots to get conserved also increases by a factor of $1.0 \quad(p<0.01)$ as shown in Table 6. The location of plots particularly proximity of plots to the residence of the household has also an effect on the continued use of SLM practices by the rural households. Plots which are spatially located near to the residency of the owners were found to have a higher chance of getting conserved. Table 6 shows that the odds ratio in favor of conserving a plot decreases by a factor 0.976 as a result of increase in the distance between a house and a farm plot by $1 \mathrm{~km}(p<0.01)$.

The result of this study indicates that the continuity of SLM practices varies across the study sites (agro-ecological zones). The households in Kaal-amin (highland) and Hintalo (midland) were more likely to continually use various conservation measures as compared to household in Begashka (lowland). The likelihood of continued use of SLM practices in Kaal-amin and Hintalo was higher by a factor of 3.68 and 4.5, respectively compared to that in Begashka (Table 6).

The distance between the residence of households and the office of extension service was considered as a proxy variable to analyze the association between extension service and continued use of sustainable land management practices. The binary logit result shows that the odds ratio in favor of continued use of SLM practices decreases by a factor of 0.979 as a consequence of increasing the distance between the extension office and households residency by $1 \mathrm{~km}(p<0.01)$.

\section{Determinants for the choices of SLM practices}

The correlation regression among the dependent variables (the four SLM practices) shows that there is interdependence among the SLM practices implemented by rural households (Table 7). For instance, there is a negative correlation between indigenous conservation and the remaining three land conservation types (physical, agroforestry, and agronomic), which implies that the former one can be substituted by the latter ones. In contrast, a positive correlation was found among physical, agroforestry, and agronomic practices, which attests their complementarity (Table 7). It is also important to note that a farmer can introduce multiple SLM practices on a given plot. For this reason, the study adopted multivariate probit model and the results are presented in Table 8 . The availability of labor force is shown to have a positive influence on the choice of physical conservation which is significant at $10 \%$ level of significance but not at $5 \%$ or less, whereas it was negatively associated with the use of agro-forestry practice $(p<0.05)$ (Table 8$)$. More specifically, households with greater labor force tend to prefer more of physical soil and water

Table 7 Correlation coefficient among the four SLM practices

\begin{tabular}{lllll}
\hline $\begin{array}{l}\text { Types of SLM } \\
\text { practices }\end{array}$ & Agronomic & Physical & Agroforestry & Indigenous \\
\hline Agronomic & 1.00 & & & \\
Physical & 0.5 & 1.00 & & \\
Agroforestry & 0.18 & 0.3 & 1.00 & \\
Indigenous & -0.65 & -0.79 & -0.22 & 1.00 \\
\hline
\end{tabular}


Table 8 Coefficient estimates of the multivariate probit model ( $p$ values in parentheses)

\begin{tabular}{|c|c|c|c|c|}
\hline \multirow[t]{2}{*}{ Explanatory variables } & \multicolumn{4}{|c|}{ Dependent variables (choice of SLM practices) } \\
\hline & Physical measures & Agoforestry & Agronomic & Indigenous \\
\hline \multicolumn{5}{|l|}{ Households characteristics } \\
\hline Years of schooling & $-0.043(0.25)$ & $-0.055(0.1)$ & $-0.0014(0.9)$ & $0.075(0.1)$ \\
\hline Labor availability & $0.099(0.07)$ & $-0.217(0.02)$ & $-0.056(0.5)$ & $0.1009(0.36)$ \\
\hline Dummy male & $-0.185(0.5)$ & $0.275(0.86)$ & $0.673(0.05)$ & $-0.972(0.01)$ \\
\hline \multicolumn{5}{|c|}{ Farming system-related variables } \\
\hline Plot size & $0.183(0.04)$ & $0.027(0.75)$ & $0.017(0.81)$ & $-0.204(0.04)$ \\
\hline Farm input & $0.00025(0.08)$ & $0.00032(0.01)$ & $0.00022(0.08)$ & $-0.00035(0.04)$ \\
\hline Irrigation access & $0.33(0.45)$ & $0.468(0.1)$ & $0.015(0.96)$ & $-2.979(0.97)$ \\
\hline Zero-grazing & $0.943(0.000)$ & $0.101(0.74)$ & $-0.119(0.68)$ & $-0.742(0.03)$ \\
\hline \multicolumn{5}{|c|}{ Plot level attributes and agro-ecology } \\
\hline $\begin{array}{l}\text { Gentle slope } \\
\text { (steep as a reference) }\end{array}$ & $-0.426(0.09)$ & $0.662(0.04)$ & $0.700(0.03)$ & $-0.472(0.2)$ \\
\hline $\begin{array}{l}\text { Medium slope } \\
\text { (steep as a reference) }\end{array}$ & $-0.38(0.1)$ & $0.398(0.1)$ & $0.576(0.04)$ & $-0.329(0.34)$ \\
\hline $\begin{array}{l}\text { Begashka } \\
\text { (Hintalo as a reference) }\end{array}$ & $1.747(0.000)$ & $0.28(0.5)$ & $0.16(0.71)$ & $-2.463(0.000)$ \\
\hline $\begin{array}{l}\text { Kaal-amin } \\
\text { (Hintalo as a reference) }\end{array}$ & $1.666(0.000)$ & $-0.58(0.1)$ & $-0.311(0.48)$ & $-2.672(0.000)$ \\
\hline \multicolumn{5}{|c|}{ Institutional supports and infrastructure } \\
\hline Extension service & $-0.008(0.02)$ & $-0.00068(0.8)$ & $-0.00016(0.96)$ & $0.011(0.01)$ \\
\hline Market access & $0.001(0.8)$ & $-0.008(0.06)$ & $-0.006(0.1)$ & $0.003(0.5)$ \\
\hline Credit access & $-0.655(0.002)$ & $0.428(0.09)$ & $0.527(0.03)$ & $-0.412(0.1)$ \\
\hline Constant & $0.194(0.85)$ & $-2.111(0.06)$ & $-1.693(0.08)$ & $0.954(0.42)$ \\
\hline Model summary & Log likelihood = 184.11 & $\begin{array}{l}\text { Likelihood ratio test } \\
\text { Chi }^{2}(21)=16.7 \text {, Prob }>\text { chi }^{2}=0.000\end{array}$ & Prob $>$ chi $^{2}=0.0011$ & Log likelihood $=-184.11$ \\
\hline
\end{tabular}

conservation measures such as terraces but are less interested in agroforestry practices.

The preference towards the physical conservation practice was found to be influenced by the size of farm plots operated by smallholder farmers. Table 8 shows that households who operate relatively larger plot size were more likely to practice physical conservation structures $(p<0.05)$ and less likely to practice indigenous conservation measures $(p<0.05)$.

The utilization of farm input was found to be very important in terms of explaining the choice of households towards various sustainable land management practices. It was found to positively influence the choice of smallholder farmers toward practicing physical conservation structures, agroforestry practice, and agronomic practice but with different levels of significance. Households who spend more money to acquire inputs are more likely to prefer physical conservation practices, agronomic practices $(p<0.1)$, and agroforestry practices as well $(p<$ $0.05)$. On the other hand, households with less farm input expenditure were found to choose more of indigenous conservation measures $(p<0.05)$.
Households who practice zero grazing were found to choose physical conservation structures compared to households who practice free grazing $(p<0.01)$ as shown in Table 8. The study also finds that households with irrigation access are in favor of implementing agroforestry practice. The positive association between irrigation access and the use of agroforestry practices shows that farmers are more interested to grow multipurpose trees, which are perennial, on their plots if they have access to irrigation water.

The study explored the role of agro-ecological variations on the preferences of smallholder households towards the sustainable land management practices. For this purpose, the study sites were purposively chosen from the three agro-ecological zones (highland, midland, and lowland) not only to ensure data heterogeneity but also to predict its influence. Physical conservation measures were found to be more preferred practices $(p<0.01)$, and the indigenous conservation measures are less likely to be practiced $(p<0.01)$ in lowlands (Kola-temben district) than in midland. Moreover, households in highland areas (Atsibi-wenberta district) are more likely to prefer physical conservation measures $(p<0.01)$ and less interested in agro-forestry 
$(p<0.1)$ and indigenous conservation practices $(p<0.01)$ (Table 8).

Plot level characteristics, mainly including slope, soil type, and soil quality, were included in the model to explain their association with the choice towards various SLM practices by rural households. Plots that are characterized by a gentle slope were found to be treated more of by agroforestry $(p<$ $0.05)$ and agronomic measures $(p<0.05)$ and less likely to be conserved by physical conservation structures $(p<0.1)$ as compared to plots with a steep slope (Table 8). The same can also be said for plots characterized by a medium slope as compared to plots with a steep slope except for the differences in the level of significance.

Table 8 shows that households that are located far from farmers training center are more likely to practice indigenous conservation options $(p<0.01)$ and less likely to implement physical conservation practices $(p<0.05)$. An access to credit has also an influence on farmers' decision for the choice of SLM practices as it carries positive coefficient for the use of agroforestry $(p<0.1)$ and agronomic practices $(p<0.05)$. In contrary, access to credit was found to have a negative influence on introducing physical conservation structures $(p<0.05)$ and indigenous conservation practices $(p<0.1)$.

\section{Impact of SLM practice on crop production}

The PSM result presented in Table 9 shows that the SLM practices introduced on farm plots have a significant influence on the productivity of farmlands. The annual value of crop production ${ }^{6}$ of continued users of the SLM practices was on average higher by ETB 17199, $25,501,23,450$, and 16,457 using nearest neighbor, radius, kernel, and stratification methods respectively as compared to non-continued users. This does mean that the continued users of SLM practices achieved annual benefits of $77 \%$ to $100 \%$ higher as compared to the non-continued users of SLM practices on average.

\section{Discussion}

The empirical findings of the current study show that farmers' decision towards the continued use and the preferences to the SLM practices are influenced by various factors. The significant predictors that explain the continued use and choice of SLM practices are discussed as follows.
Availability of labor has carried a positive coefficient for the continued use of SLM practice, which indicates that households with larger family size are relatively more willing to continual use of the SLM practices. The household can, therefore, allocate enough labor force to sustain the conservation measures through carrying out maintenance work and even by introducing new conservation practice regularly. However, there are conditions that majority of the members of family size may account for larger proportion of dependents mainly children and elders. In such condition, therefore, households with larger family size but lower labor force may tend to allocate much of their time in generating daily income such as off/non-farm incomes to cover their daily subsistence instead of investing their time and labor in conservation since the benefit from the conservation of their plots are not realized immediately. The result of the current study is consistent with the findings of Wagayehu and Drake (2003) and Pender et al. (2001) who reported that in a family with a greater number of mouths to feed, much attention is given to their immediate food requirements and less attention to soil conservation activities on the farmlands.

The availability of labor force also determines the preference of households toward the SLM options. Households with larger labor force were found to choose physical conservation over the other SLM practices. The positive effect of the abundance of labor force regarding the choices in favor of physical conservation structures, particularly terraces and bunds, is probably due to the fact that physical conservation practices usually demand substantial labor force and are labor-intensive works.

This finding was substantiated by the fact that about $75 \%$ of the respondents stated that the labor-intensive nature of the soil and water conservation structures hinders its adoption and continued use. The same view was also stressed by the key informants by describing some of the SLM practices as very tiresome. However, the negative effect of labor force on the choice to agroforestry may be attributed to the less favorable environment to introduce agro-forestry practices on private plots. Farmers may refrain from implementing agroforestry over the other conservation measures such as physical and agronomic conservation practices. This is in agreement

Table 9 Impacts of SLM practices on the crop production at household level

\begin{tabular}{lllll}
\hline Matching methods & Treated observations & Control observations & Average treatment effect on treated (ATT) & $t$ value \\
\hline Nearest neighbor & 115 & 59 & 17,199 & $1.9^{* *}$ \\
Radius & 115 & 115 & 25,501 & $3.4^{* * *}$ \\
Kernel & 115 & 115 & 23,450 & $3.3^{* * *}$ \\
Stratification & 115 & 115 & 16,457 & $1.65^{*}$ \\
\hline
\end{tabular}

$* * *, * *,{ }^{*}$ denotes values significant at $1 \%, 5 \%$, and $10 \%$, respectively 
with the findings from different regions of Ethiopia and other developing regions (Asrat et al. 2004; Clay et al. 1998; Gebremedhin and Swinton 2003; Jara-Rojas et al. 2012; Pender and Gebremedhin 2007) who reported a positive relationship between availability of labor force and continued use of stone bunds and other terraces.

Plot size (crop field) was found to negatively influence the decision of households to the overall continued use of SLM practices. A household who operates larger size of farmland definitely need high labor and time to keep the introduced conservation measures well maintained, and also to improve the fertility status of the farmlands (for compost and manure application). These activities may demand a significant labor force and put much burden on the farm households since they are busy in different farm and other social-related activities in which such pressure may enforce them to discontinue the use of some of the sustainable land management practices. Regarding the preferences, households who possess a larger plot size were in favor of using physical conservation over the other conservation measures. The positive correlation between large plots and choosing physical conservation measures could probably be due to the reason that most of the physical SLM practices take proportionally more space on small plots and the benefit from conservation on such plots may not be enough to compensate for the decline in production due to the loss in the area devoted to conservation structures. Similar results have been reported from other regions of the country (Bekele and Drake 2003; Birhanu and Meseret 2013; Enki et al. 2001; Mengstie 2009; Tesfaye et al. 2014; Teshome 2014) in which plot size was negatively associated with the implementation of soil and water conservation structures.

Farming systems were also found to be very instrumental in determining the continued use of and preferences towards the set of SLM practices. The results of the current study give an impression that farming systems mainly the amount of farm inputs deployed and zero-grazing practice are found to be very helpful for the continued use and choices of SLM practices. The highly significant influence of farm input expenditure on the continued use signifies the complementarity of modern farm input application and other SLM practices implemented at plot level. Farm input utilization, mainly application of chemical fertilizer and improved seeds, is usually supported by soil and water conservation so as to boost crop yield. Furthermore, the positive association between zero grazing and the overall continuity of SLM practices is among the most interesting findings of this study. The zero grazing policy that has been adopted by the government of Ethiopia could directly help in promoting SLM practices since it limits the mobility of livestock in the conserved areas, which otherwise could destroy the introduced SLM practices. In line with the findings of the current study, Kassie et al. (2008) reveals that households who practice zero grazing tend to continually use SLM practice. Regarding the effect of modern farm input utilization on the choice of SLM practices, the results imply that households who spend more to acquire farm inputs are also willing to use physical structures, agronomic and agroforestry practices. This does mean that the effect of farm input utilization on the preference of the set of SLM is indifferent which also mean that the practices are equally preferred by the household.

This study shows mixed results regarding the influence of plot level characteristics both on the continued use and the choice of SLM decisions by rural households. For instance, topographic location of plots was found to have an influence on the choice regarding which type of SLM practice to deploy, but shows no significant influence on the continued use of SLM practices. The results also find that plots that are located in a flat and moderately flat topography are less likely to be conserved using physical conservation structures compared to farm lands located at a steep topography. This does mean that farm plots with gentle and medium slopes are less likely to be treated by physical conservation structures compared to plots with steep slopes. This is probably due to the reason that plots characterized by a steep slope are more vulnerable to soil erosion emanated from high speed of runoff because of the rugged terrains. In order to deter such erosion problems, farmers may prefer physical soil and water conservation structure, particularly bunds and terraces. Moreover, the relatively gentle and medium slope farm plots were found to be more likely to receive agronomic and agroforestry conservation which signals that conservation-based agriculture is practiced in fairly flat and undulating flat locations. The current results are parallel to the finding of Kassie et al. (2008) who reported that conservation-based agricultural practices are mostly implemented in plots with a moderate and a gentle slope.

The positive influence of proximity of farm plots to the residency of the owner on the continued use of SLM indicates that plots that are placed in a near distance from the residency have higher chance of frequent visit and follow-up and thereby higher chance of getting treated with the conservation structures regularly. Previous studies in this regard have reported mixed results. Amsalu and de Graaff (2007) and Kassie et al. (2009) asserted that practicing soil and water conservation measures were positively associated with the distance of plots to residency. This is consistent with the findings of the current study. In contrast, a negative association between distance of plot and adoption of SLM practices mainly agronomic conservation practices has 
been reported by Benin (2006), Mengstie (2009), Pender and Gebremedhin (2007), and Teklewold et al. (2013).

The influence of access to infrastructures particularly credit access, extension service, and access to irrigation facility were found to be very effective in explaining the preferences of households towards SLM practices but not for the overall continued use. The positive effect of credit access to the choice of agroforestry and agronomic practices implies that farmers tend more to allocate borrowed money to buy inputs such as improved varieties of fruit trees for agroforestry, improved seed of cereal crops, and fertilizers. Besides, the positive association between agroforestry and access to irrigation signals that most of the time perennial crops/fruit trees are grown for agroforestry purpose which needs to be supplemented by irrigation during the long dry season in the study sites. Other studies in this regard reported similar results. In Chile, for instance, access to credit positively affected the use of soil and water conservation activities (Jara-Rojas et al. 2012). Similarly, extension service has a positive influence on the continuity of SLM on individual farm plots in central Ethiopia (Moges and Taye 2017; \& Bonger et al 2004), which is parallel to the results of the current study.

Looking at the productivity impact of SLM practices, the present study finds a significant variation in the value of crop production between continued and non-continued users of SLM practices. The PSM results show that the value of crop production of SLM users was $77-100 \%$ higher than that of non-continued users on average. The descriptive statistics result also substantiated this finding. The average crop yield (2016/17 production year) of SLM user households was 14 quintal/ household while it was 10.5 quintal for the non-continued users on average. It was observed that the average amount of crop yield of continued users of SLM practices was $33.3 \%$ higher than that of non-continued users. Introducing more than one conservation measure on a given farm plot was also associated with a higher crop yield. For instance, it was found that the average crop yield (2016/17 production year) of households who practice multiple land conservation was 15 quintals/household, which is significantly higher than the average yield of total SLM user respondents. This does mean that the crop yield of households who practiced multiple SLM was found to be higher by $42.8 \%$ compared to the non-continued users of SLM practices. Such considerable yield increase gives the impression that the productivity effect of one conservation measure is enhanced by the use of the others, which in turn confirms the presence of complementarity among the SLM practices. The strong positive association between the amount of crop yield and continued use of SLM practices could perhaps be due to the fact that households who produce more are ready to invest on conservation of farm plots to keep the productivity as high as possible. In addition, the benefits from farmland conservation may be enough to compensate for the costs incurred in association to implementing some of the SLM practices. The result of the current study is consistent with the findings of Kassie et al. (2008) who reported a significant crop yield increment as a result of introducing soil and water conservation practices on farm plots.

\section{Conclusion}

The results of the current study confirms that the implementation of various sustainable land management practices are influenced by farming technologies deployed by rural households, agro-ecological variations, plot characteristics, and institutional supports. The findings further affirm that most of the SLM practices are complementary to one another, and practicing of two or more SLM practices in a given plot is found to be highly associated with higher value of crop production. Such complementarity highlights that the productivity effect of a given SLM practice is enhanced by the use of the others. This in turn provides an incentive for a multiple use of SLM practices on farm plots. More importantly, a considerable increase in value of crop production was observed in plots which are treated with multiple SLM practices. This may also pose a considerable incentive for rural households to conserve their plots.

The findings of this study give the impression that the implementation approaches for the SLM practices should be as diverse as the farming techniques, household attributes, and plot level features so that the SLM practices can be integrated with the day-to-day farming operations of the households. This will eventually create self-motivated individuals who can persistently conserve their farmlands even in the absence of public support for the costs of the SLM implementation.

\section{Endnotes}

${ }^{1}$ District and wereda are interchangeably used throughout the paper. District is a synonymous to what is locally known as wereda, the second smallest administration unit in Tigrai, Ethiopia

${ }^{2}$ The first criterion to select the study catchments was size of farm plots that are well treated with various SLM practices. The second criterion was experience and availability of self-motivated farmers who continues to maintain terraces on their private plots

${ }^{3}$ The smallest administration unit in Tigrai region in rural settings

${ }^{4}$ Households for control observations were randomly drawn from other three selected adjacent catchments 
in which plots are poorly treated from respective study sites.

${ }^{5}$ To better understand the details on the nature and application of multivariate probit model, including its application on preferences of SLM practice, we suggest to see Dorfman (1996), Greene (2003), Aurier and Mejia (2014), and Cappellari and Jenkins (2003)

${ }^{6}$ The value of crop production was computed by multiplying the total produce of each crop by its prevailing local market price.

\section{Acknowledgements}

This research work was funded by Mekelle University (project registration number-CRPO/CoDANR/SM/005/09) and we acknowledge for that. We are also very thankful to the respondents who participated in the survey.

\section{Funding}

The fund for data collection was obtained from Mekelle University.

\section{Availability of data and materials}

The raw data will be made available upon request.

\section{Authors' contributions}

HE has developed the concept, designed the study, interpreted the results, and wrote the manuscript. TN participated in the study design, data analysis, and write up. MA participated in developing the data collection tools and technically supported the data analysis and the write up. The authors read and approved the final manuscript.

\section{Ethics approval and consent to participate}

Not applicable.

\section{Consent for publication}

Not applicable.

\section{Competing interests}

The authors declare that they have no competing interests.

\section{Publisher's Note}

Springer Nature remains neutral with regard to jurisdictional claims in published maps and institutional affiliations.

Received: 25 September 2018 Accepted: 15 March 2019

Published online: 29 April 2019

\section{References}

Adimassu Z, Kessler A (2012) Farmers' investments in land management practices in the central Rift Valley of Ethiopia. In: Paper presented to the 8th international symposium agro environ 1-4 may 2012, Wageningen, Netherlands

Adimassu Z, Langan S, Johnston R (2016) Understanding determinants of farmers' investments in sustainable land management practices in Ethiopia: review and synthesis. Environ Dev Sustain 18:1005-1023

Adugna G, Bekele W (2007) Determinants of land degradation in the Lake Tana Basin and its implications for sustainable land management. The Case of Angereb And Gish-Abbay Watersheds

Amsalu A, de Graaff J (2007) Determinants of adoption and continued use of stone terraces for soil and water conservation in an Ethiopian highland watershed. Ecol Econ 6:294-302

Asrat P, Belay K, Hamito D (2004) Determinants of farmers' willingness to pay for soil conservation practices in the southeastern highlands of Ethiopia. Land Degrad Dev 15:423-438

Aurier P, Mejia V (2014) Multivariate Logit and Probit models for simultaneous purchases: presentation, uses, appeal and limitations. https://doi.org/10.1177/ 2051570714535531

Bekele E (2003) Causes and consequences of environmental degradation in Ethiopia. In: Gedion A (ed) Environment and environmental change in
Ethiopia. Consultation Papers on Environment No. 1. Forum for Social Studies, Addis Ababa, pp 24-31

Bekele W, Drake L (2003) Soil and water conservation decision behaviour of subsistence farmers in the eastern highlands of Ethiopia: a case study of the Hunde-Lafto area. Ecol Econ 46:437-451

Belay KT, Van Rompaey A, Poesen J, Van Bruyssel S, Deckers J, Amare K (2015) Spatial analysis of land cover changes in eastern Tigray (Ethiopia) from 1965 to 2007: are there signs of a Forest transition. Land Degrad Dev. https://doi. org/10.1002/ldr.2275

Benin S (2006) Policies and programmes affecting land management practices, input use, and productivity in the highlands of Amhara region, Ethiopia. In: Pender J, Place F, Ehui S (eds) Strategies for sustainable land management in the East African highlands. International Food Policy Research Institute, Washington, DC

Berry L (2003) Land degradation in Ethiopia: its extent and impact. A study commissioned by the GM with WB support

Bewket W (2003) Towards integrated watershed management in Highland Ethiopia: the Chemoga watershed case study. Tropical Resource Management Papers, No. 44. Wageningen University, Wageningen, Netherlands

Bewket W (2007) Soil and water conservation intervention with conventional technologies in northwestern highlands of Ethiopia: acceptance and adoption by farmers. Land Use Policy 24:404-416

Birhanu A, Meseret D (2013) Structural soil and water conservation practices in Farta District, North Western Ethiopia: an investigation on factors influencing continued use. Science, Technology and Arts Research Journal 2(4):114-121

Bojo J, Cassells D (1995) Land degradation and rehabilitation in Ethiopia: a reassessment. The World Bank, Washington, DC

Bonger T, Ayele G, Kumsa T (2004) Agricultural extension, adoption, and diffusion in Ethiopia, Ethiopian Development Research Institute (EDRI) Research Report, No. 1. EDRl, Addis Ababa

Cappellari L, Jenkins SP (2003) Multivariate probit regression using simulated maximum likelihood. Stata J 3:278-294

Clay DC, Reardon T, Kangasniemi J (1998) 'Sustainable intensification in the highland tropics: Rwandan farmers' investments in land conservation and soi fertility. Econ Dev Cult Chang 46(2):351-378

Diagana B (2003) Working paper on Land Degradation in Sub Saharan Africa: What Explains the Widespread Adoption of Unsustainable Farming Practices. Montana State University

Dorfman JH (1996) Modeling multiple adoption decisions in a joint framework. Am J Agric Econ 78:547-557

Enki M, Kassa Belay K, Dadi L (2001) Determinants of adoption of physical soil conservation measures in central highlands of Ethiopia the case of three districts of North-Shewa. Agricultural Economics Research, Policy and Practice in Southern Africa 40(3):293-315

Eyasu E (2003) National assessment on environmental roles of agriculture in Ethiopia. Unpublished Research Report Submitted to EEA, Addis Ababa

FAO (2011). Sustainable land management practices. Available at: www.fao.org/ docrep/014/i1861e/i1861e.pdf. Accessed on September, 2017

Garson, David, (2008) Logistic_Regression.pdf, North Carolina State University. Available at: http://www2.chass.ncsu.edu/garson/PA765/logistic.htm. Accessed on Aug 2017

Gebremedhin B, Swinton S (2003) Investment in soil conservation in northern Ethiopia: the role of land tenure security and public programs. Agric Econ 29: 69-84

Genanew BW, Alemu M (2012) Investments in land conservation in the Ethiopian highlands: a household plot-level analysis of the roles of poverty, tenure security, and market incentives. Discussion Paper Series. Environment for Development Available at: http://www.efdinitiative.org/sites/default/files/efddp-10-09.pdf

Gesellschaft für Internationale Zusammenarbeit (GIZ) (2014) Lessons and experiences in sustainable land management. GIZ Ethiopia, Addis Ababa, Ethiopia

de Graaff J, Amsalu A, Bodnar F, Kessler A, Posthumus H, Tenge A (2008) Factors influencing adoption and continued use of long-term soil and water conservation measures in five developing countries. Appl Geogr 28:271-280

Greene W (2003) Econometric analysis, fifth edn. Pearson Education Ltd, New Jersey

Hurni H, Wiesmann U, and with an international group of co-editors (2010) Global Change and Sustainable Development: A Synthesis of Regional Experiences from Research Partnerships. Berne, Switzerland: Geographica Bernensia. University of Bern. 
Jara-Rojas R, Boris E, Ureta B, Díaz J (2012) Adoption of water conservation practices: a socioeconomic analysis of small-scale farmers in Central Chile. Agric Syst 110:54-62

Kassie M (2009) Policy brief on where does sustainable land management practices work: a comparative study. Environment for Development Initiative, Addis Ababa

Kassie M, Jaleta M, Shiferaw B, Mmbando F, Mekuria M (2013) Adoption of interrelated sustainable agricultural practices in smallholder systems: evidence from rural Tanzania. Technol Forecasting Soc 80:525-540

Kassie M, Zikhali P, Manjur K, Edwards S (2009) Adoption of sustainable agriculture practices: evidence from a semi-arid region of Ethiopia. Nat Res Forum 33:189-198

Kassie et al (2008) Sustainable land management practices improve agricultural productivity. Policy brief: Environmental Economics, Policy Forum for Ethiopia, Addis Ababa

Kirui OK, Mirzabaev A (2015) Drivers of land degradation and adoption of multiple sustainable land management practices in Eastern Africa. 29th International Conference of Agricultural Economists, Milan

Mengstie FA (2009) Assessment of adoption behavior of soil and water conservation practices in the Koga watershed, highlands of Ethiopia. Unpublished M.Sc. Thesis, Cornell University Available at: http://citeseerx.ist. psu.edu/viewdoc/download?doi=10.1.1.473.7094\&rep=rep1\&type=pdf

Miheretu BA, Yimer AA (2017) Determinants of farmers' adoption of land management practices in Gelana subwatershed of northern highlands of Ethiopia. Ecol Process 6:19

Moges DM, Taye AA (2017) Determinants of farmers' perception to invest in soil and water conservation technologies in the North-Western highlands of Ethiopia. International Soil and Water Conservation Research 5:56-61

Nkonya E, Von Braun J, Alisher M, Bao Le Q, Ho Young K, Kirui O, Edward K (2013) Economics of land degradation initiative: methods and approach for global and National Assessments. ZEF- discussion papers on development policy no. 183, Bonn

Pender J, Gebremedhin B (2006) Land management, crop production and household income in the highlands of Tigray, northern Ethiopia: an econometric analysis. In: Pender J, Place F, Ehui S (eds) Strategies for sustainable land management in the east African highlands. International Food Policy Research Institute, Washington, DC

Pender J, Gebremedhin B (2007) Determinants of agricultural and land management practices and impacts on crop production and household income in the highlands of Tigrai, Ethiopia. J Afr Econ 17:395-450

Pender JG, Berhanu G, Benin S, Ehui S (2001) Strategies for sustainable development in the Ethiopian highlands. Am J Agric Econ 83(5):1231-1240

Pingali P, Schneider K, Zurek M (2014) Poverty, Agriculture and the Environment: The Case of Sub-Saharan Africa. In: Marginality. Springer, Berlin

Shiferaw B, Holden TS (1998) Resource degradation and adoption of land conservation technologies in the highlands of Ethiopia: a case study of Andit Tid, north Sheawa. Agric Econ 18:233-247

Tadesse M, Belay K (2004) Factors influencing adoption of soil conservation measures in southern Ethiopia: the case of Gununo area. J Agric Rural Dev Trop Subtrop 105:49-62

Teklewold H, Kassie M, Shiferaw B (2013) Adoption of multiple sustainable agricultural practices in rural Ethiopia. J Agric Econ 64:597-623

Tesfaye A, Negatu W, Brouwer R, Van der Zaag P (2014) Understanding soil conservation decision of farmers in the Gedeb watershed, Ethiopia. Land Degrad Dev 25:71-79

Teshome A (2014) Tenure security and soil conservation investment decisions: empirical evidence from East Gojam, Ethiopia. J Dev Agric Econ 6(1):22-32

Tongul H, Hobson M (2013) Scaling up an integrated watershed management approach through social protection programmes in Ethiopia: the MERET and PSNP schemes

von Braun J, Gerber N, Mirzabaev A, Nkonya EM (2013) The economics of land degradation (No. 147910). University of Bonn, Center for Development Research (ZEF), Bonn

von Braun J, Algieri B, Kalkuhl M (2014) World food system disruptions in the early 2000s: causes, impacts and cures. World Food Policy 1(1):1-22

Wagayehu B, Drake L (2003) Soil and water conservation decision behaviour of subsistence farmers in the eastern highlands of Ethiopia: a case study of the Hunde-Lafto area. Department of Economics, Swedish University of Agricultural Sciences, Uppsala, pp 437-451

WOCAT (2005) World overview of conservation approaches and technologies. Available at http://www.wocat.net/about1.asp
World Bank (2007) Review on the determinants of the adoption of sustainable land management practices and their impacts in the Ethiopian highlands, New York

Yirga C (2007) The dynamics of soil degradation and incentives for optimal management in central highlands of Ethiopia. Unpublished Ph.D. thesis. Department of Agricultural Economics, Extension, and Rural Development. University of Pretoria, South Africa Available at: https://repository.up.ac.za/ bitstream/handle/2263/25333/Complete.pdf?sequence $=6$

\section{Submit your manuscript to a SpringerOpen ${ }^{\circ}$ journal and benefit from:}

- Convenient online submission

- Rigorous peer review

- Open access: articles freely available online

- High visibility within the field

- Retaining the copyright to your article

Submit your next manuscript at $\boldsymbol{\nabla}$ springeropen.com 